\title{
Toxicity of different Fusarium mycotoxins on growth performance, immune responses and efficacy of a mycotoxin degrading enzyme in pigs
}

\author{
Yeong-Hsiang CHENG ${ }^{\mathrm{a}}$, Ching-Feng WENG ${ }^{\mathrm{b}}$, Bao-Ji CHEN ${ }^{\mathrm{c}}$, \\ Ming-Huang CHANG ${ }^{\mathrm{d} *}$ \\ ${ }^{a}$ Department of Animal Science, National I-Lan University \#1, Sheng-Lung Rd., I-Lan 260, Taiwan \\ ${ }^{\mathrm{b}}$ Institute of Biotechnology, National Dong-Hwa University, Hualien, Taiwan \\ ${ }^{\mathrm{c}}$ Department of Animal Science, National Taiwan University, Taipei, Taiwan \\ ${ }^{\mathrm{d}}$ Department of Veterinary Medicine, National Chia-Yi University, Chia-Yi, Taiwan
}

(Received 12 August 2005 - Accepted 30 May 2006)

\begin{abstract}
This study was aimed at investigating the effects of a defined concentration of Fusarium mycotoxins, deoxynivalenol (DON) and zearalenone (ZON) incorporated into feeds on growth performance, blood biochemistry, and immune response of pigs and the alleviating effects of a mycotoxin degrading enzyme (MDE) on the toxicity of Fusarium mycotoxins. A total of 48 weaning pigs was randomly allotted to four treatments (two replicates per treatment) including a control, Toxins (1 ppm DON and $250 \mathrm{ppb}$ ZON), Toxin+MDE (1 ppm DON, $250 \mathrm{ppb}$ ZON and $1.5 \mathrm{~kg}$ MDE per ton of feed), and MDE alone ( $1.5 \mathrm{~kg}$ per ton of feed) for a 6 week challenged trial. The results in different criteria including growth performance, serum biochemistry parameters, alveolar macrophage activity, antibody titers of pseudorabies (PR) vaccine and cytokine secretion profile showed that DON and ZON consistently impaired pigs after 6 week exposure. Based on these findings, we suggest that the combination of DON and ZON confers a chemical multi-organ toxicity in pigs and MDE provides a partial or complete toxic sparing effect of mycotoxins.
\end{abstract}

deoxynivalenol / zearalenone / growth performance / immune function / pigs

Résumé - Toxicité de différentes mycotoxines de Fusarium sur les performances de croissance et les réponses immunitaires ainsi que l'efficacité d'une enzyme dégradant ces mycotoxines chez le porc. Cette étude avait pour but d'étudier les effets d'une concentration définie de mycotoxines de Fusarium (déoxynivalénol (DON) et zéaralénone (ZON)) incorporées dans l'alimentation sur les performances de croissance, les paramètres sanguins et les réponses immunitaires des porcs ainsi que les effets d'une enzyme dégradant ces mycotoxines (MDE) sur leur toxicité. Un total de 48 porcs sevrés a été aléatoirement soumis à quatre traitements (deux réplicats par traitement) incluant un traitement témoin, un traitement toxines ( $1 \mathrm{ppm}$ DON et $250 \mathrm{ppb} \mathrm{ZON}$ ), un traitement toxines+MDE (1 ppm DON, $250 \mathrm{ppb} Z \mathrm{ZON}$ et 1,5 $\mathrm{kg}$ de MDE par tonne d'aliment) et un traitement

\footnotetext{
*Corresponding author: cmh@mail.ncyu.edu.tw
} 
MDE seule (1,5 kg par tonne d'aliment) sur une durée expérimentale de 6 semaines. Les résultats des différents critères que sont les performances de croissance, les paramètres biochimiques du sérum, l'activité des macrophages alvéolaires, les taux d'anticorps dirigés contre la maladie d'Aujeszky (PR) et le profil de sécrétion des cytokines ont montré que DON et ZON ont engendré un affaiblissement régulier chez les porcs après 6 semaines d'expérimentation. Les résultats obtenus suggèrent que la combinaison de DON et ZON engendre une toxicité chimique multi-organes chez les porcs et que MDE annihile partiellement ou complètement les effets toxiques de ces mycotoxines.

\section{déoxynivalénol / zéaralénone / performance de croissance / réponse immunitaire / porc}

\section{INTRODUCTION}

The effect of non macrocyclic trichothecenes in pigs has been studied using several methodologies including the dietary incorporation of crude fungal cultures with known levels of mycotoxins, the preparation of rations with naturally contaminated feedstuffs containing a known toxic concentration, or the addition of pure mycotoxins to uncontaminated diets. The use of raw fungal culture materials, crude extracts and naturally contaminated grains may be involved in the possibility of adding unknown metabolites with dangerous toxic effects that usually lead to confounding results. However, the most representative approach for testing this fact is the incorporation of certain amounts of highly purified mycotoxins into uncontaminated diets $[19,21]$. Deoxynivalenol and fusaric acid have been shown to sequentially elevate brain tryptophan, serotonin (5-hydroxytryptamine, 5-HT), and 5-hydroxyindoleacetic acid (5-HIAA) concentrations, and these neurotransmitters can lead to a decrease in feed intake [26, 29, 33].

Zearalenone (ZON) and its metabolites ( $\alpha$ - and $\beta$-zearalenol), $\alpha$-zearalenol is the predominant metabolite of $\mathrm{ZON}$ in pigs, whereas insusceptible animals (broilers, cows and sheep) produce more amounts of the less active $\beta$-zearalenol [23]. The $\mathrm{ZON}$ and its metabolites disrupt reproductive processes via mimicking of the action of estradiol-17 $\beta$ [10] depending on the reproductive status (pre-pubertal, cycling or pregnant) of the affected animal [12]. Prepubertal gilts consuming a milo diet contaminated with $1.8 \mathrm{ppm} \mathrm{ZON}$ exhibits puberty at a younger age without an alteration in conception rates, ovulation rates or embryonic survival $[11,27]$. However, a different result from a previous study also indicates the delay of puberty in gilts [8]. With regards to the effects on feed intake and growth performance, the results on fusarium mycotoxin contaminated maize based diets (1.2 mg ZON and $8.6 \mathrm{mg}$ DON per kg maize) show that voluntary feed intake and subsequent body weight gain of the animals receiving the highest proportion of Fusarium toxin contaminated maize are significantly decreased while the feed conversion ratio was not affected by the treatment [7]. The critical values of DON and $\mathrm{ZON}$ in feed of farm animals are $1 \mathrm{mg}$ DON per kg feed and $0.25 \mathrm{mg} \mathrm{ZON}$ per $\mathrm{kg}$ feed for starting and finishing pig diets and $0.05 \mathrm{mg}$ per $\mathrm{kg}$ feed for pre-pubertal female breeding pigs [3]. The aim of this experiment was to investigate the effects of a defined concentration of DON and ZON on growth performance, blood biochemistry, and immune response of pigs and an antimycotoxin enzyme (MDE) was tested for the alleviating efficacy of Fusarium mycotoxin toxicity.

\section{MATERIALS AND METHODS}

\subsection{Animals treatment}

A total of forty-eight weaning piglets (body weight $9 \mathrm{~kg}$ ) were conducted in two 
Table I. Composition of experimental diets (asfed basis).

\begin{tabular}{lc}
\hline Ingredients & $\%$ \\
\hline Maize & 62.25 \\
Soyabean meal (CP44\%) & 22.50 \\
Fish meal (CP60\%) & 5.00 \\
Whey & 6.00 \\
Dicalcium phosphate & 1.85 \\
Limestone, pulverized & 1.00 \\
Salt & 0.50 \\
L-Lysine & 0.25 \\
DL-Methionine & 0.07 \\
Choline chloride, 50\% & 0.08 \\
Vitamin premix ${ }^{1}$ & 0.30 \\
Trace mineral premix ${ }^{1}$ & 0.20 \\
& \\
Calculated nutrient composition & \\
Metabolizable energy (kcal per kg) & 3270 \\
Crude protein (\%) & 19.10 \\
Lysine (\%) & 1.12 \\
Sulfur amino acid (\%) & 0.79 \\
Total phosphorus (\%) & 0.74 \\
Calcium (\%) & 0.83 \\
\hline
\end{tabular}

${ }^{1}$ Provided per kilogram of diet: vitamin A (retinyl palmitate), $5000 \mathrm{IU}$; cholecalciferol, $500 \mathrm{IU}$; vitamin E (DL- $\alpha$-tocopheryl acetate), $20 \mathrm{IU}$; vitamin $\mathrm{K}_{3}, 1.25 \mathrm{mg}$; thiamin, $4.2 \mathrm{mg}$; riboflavin, $4.0 \mathrm{mg}$; pantothenic acid, $15.2 \mathrm{mg}$; niacin, $37.3 \mathrm{mg}$; pyridoxine, $6.0 \mathrm{mg}$; choline, $1320 \mathrm{mg}$; folic acid, $1.4 \mathrm{mg}$; biotin, $0.23 \mathrm{mg}$; vitamin $\mathrm{B}_{12}, 15 \mu \mathrm{g}$; ethoxyquin, $120 \mathrm{mg}$; manganese, $35 \mathrm{mg}$; zinc, $133 \mathrm{mg}$; iron, $123 \mathrm{mg}$; and copper, $23 \mathrm{mg}$.

batches. The animals were obtained from a pseudorabies free breeder farm. They were randomly allotted to four treatments. One pen was raised with 4 pigs, and 3 pens for each treatment. The following trial set-up was used: Control group (mycotoxin free, no MDE); Toxins (1 ppm DON, $250 \mathrm{ppb} Z \mathrm{ZON}$ ); Toxins+MDE (1 ppm DON, $250 \mathrm{ppb} Z \mathrm{ZON}, 1.5 \mathrm{~kg}$ MDE per ton of feed); MDE alone (1.5 kg MDE alone per ton of feed). The MDE product was a kind of mycotoxin degradation enzyme with esterase, epoxidase and peptidase activity.
The basal diet (Tab. I) was primarily based on maize with soybean meal and was formulated according to NRC 1988 nutrient requirements. During the experiment, feed and water were provided ad libitum through the 6-week experimental period.

\subsection{Mycotoxin preparation}

DON (5 mg per g) and ZON (1.23 mg per g) used in this study were kindly provided by Biopure (IFATulln, Austria) and they were fermented in wheat and barley by the fungi inoculation procedure. The content of mycotoxins incorporated in different treatments was sampled and analyzed by HPLC methods. For the mycotoxin assays in feed, less than $0.01 \mathrm{ppm}$ DON and $10 \mathrm{ppb} \mathrm{ZON}$ in the control and MDE alone group, $1.04 \mathrm{ppm}$ DON and $263 \mathrm{ppb} \mathrm{ZON}$ in the Toxins group, and $1.02 \mathrm{ppm}$ DON, $254 \mathrm{ppb} \mathrm{ZON}$ in the Toxins+MDE group were detected.

\subsection{Growth performance determination}

Zootechnical parameters: the body weights and feed intakes of the pigs were measured at the 16th, 28th day and the end of the experiment. Body weight gain, feed intake, and feed utilization efficiency were calculated based on these data. Mortality was also recorded, and accumulated mortality was calculated at the end of the experimental period. Three pigs were sacrificed per pen for the following determinations.

\subsection{Immune function evaluation}

\subsubsection{Alveolar macrophage chemotaxis and phagocytosis}

Alveolar macrophages were collected from the pigs by bronchi alveolar lavage 
(BAL) with phosphate-buffered saline (PBS). Alveolar macrophages were purified from the BAL specimen by centrifugation for $30 \mathrm{~min}$ at $900 \times g$ on a gradient (Histopaque-1083, Sigma Diagnostics, Inc., St. Louis, MO). The macrophages were further purified in tissue culture flasks with RPMI-1640 supplemented with 5\% bovine serum albumin, $1 \%$ sodium pyruvate, $1 \%$ L-glutamine, $1.4 \%$ MEM nonessential amino acids, and $1 \%$ antibiotic-antimycotic solution (Sigma). Two hours after the cells were plated, unbound cells were removed by washing three times with RPMI-1640 medium, and bound alveolar macrophages were collected by treatment with $3 \times$ trypsin-EDTA $(0.15 \%$ trypsin and $1.50 \mathrm{mM}$ EDTA in PBS, $\mathrm{pH}$ 7.2). The chemotactic function of alveolar macrophages was measured by the Boyden chamber technique. A cell culture insert containing a polyethylene terephthalate membrane with a pore size of $3 \mu \mathrm{m}$ served as the upper chamber and was placed in one well of a 24-well cell culture plate (Costar, Cambridge, Mass.), which served as the lower chamber. A total of $800 \mu \mathrm{L}$ of DMEM with 10,1 , or $0.1 \%$ pooled normal serum (NS) from conventionally housed pigs as the chemoattractant was added in the lower chamber; DMEM without NS was used as a negative control. Alveolar macrophages $\left(10^{6}\right.$ per $\left.\mathrm{mL}\right)$ were incubated for $30 \mathrm{~min}$ at $37{ }^{\circ} \mathrm{C}$ in DMEM without phenol red, and after incubation, $200 \mu \mathrm{L}$ of the macrophage suspension was added to the upper chamber and the macrophages were allowed to migrate for 1 to $2 \mathrm{~h}$ at $37^{\circ} \mathrm{C}$ in a $5 \% \mathrm{CO}_{2}$ atmosphere.

After removal of the cell culture insert, $200 \mu \mathrm{L}$ of MTT solution was added to the lower chamber. After $4 \mathrm{~h}$ of MTT reduction by macrophages, the cells were lysed by adding $1 \mathrm{~mL}$ of $20 \%$ (wt/vol) sodium dodecyl sulfate-50\% dimethyl formamide ( $\mathrm{pH}$ 4.7). The absorbance was read at $595 \mathrm{~nm}$. Chemotaxis was expressed as a chemotactic index, which was obtained by dividing the value for chemoattracted macrophages by the value for randomly migrated macrophages in the negative (normal saline) control.

For the phagocytosis assay, the alveolar macrophage coverslip cultures were incubated with $2 \mathrm{~mL}$ of Candida albicans suspension $\left(1 \times 10^{7}\right.$ per $\left.\mathrm{mL}\right)$ in complete medium. After $60 \mathrm{~min}$ of incubation, the coverslips were washed with sterile saline, fixed in methanol, and then stained with May-Grunwald-Giemsa stain. The percentages of phagocytoxic macrophages and average number of internalized Candida albicans per phagocytotic macrophage were determined by scoring stained coverslip cultures under microscope at $1000 \times$ magnification. A total of 200 macrophages were scored per coverslip from each treatment of three pigs.

\subsubsection{Measurements of blood biochemical parameters and antibody titers}

The pigs were vaccinated subcutaneously with one dose of pseudorabies $(\mathrm{PR})$ vaccine at weaning and received a booster two weeks later. Blood samples were taken on experimental day 14, and day 28 from three randomly selected pigs for each treatment by the vena cava duct. The PR antibody titers were measured by the Idexx test kit (IDEXX, MAINE, USA) and ELISA reader. For the assay of blood biochemical parameters, blood from three pigs per treatment was collected, and the blood was centrifuged at $2654 \times g$ for $10 \mathrm{~min}$. The sera were collected for the determination of total protein, albumin, globulin, $\gamma$-glutamyltransferase (GGT, EC 2.3.2.2), aspartate aminotransferase (AST, EC 2.6.1.1) and alanine aminotransferase (ALT, EC 2.6.1.2), by an automatic clinical chemistry analyzer (Roche, CobusMira-Plus, Roche Diagnostic System Inc., USA). 
Table II. Oligonucleotide primers for selected cytokines and iNOS gene.

\begin{tabular}{llll}
\hline \multirow{2}{*}{ Gene specificity } & \multirow{2}{*}{ Oligonucleotide sequences (5'-3') } & \multicolumn{2}{c}{ Gene sequences } \\
\cline { 3 - 4 } & & Accession number & Reference \\
\hline IL-1 $\beta$ & (S) AAAGGGGACTTGAAGAGAG & M86725 & {$[12]$} \\
\multirow{2}{*}{ IL-6 } & (AS) CTGCTTGAGAGGTGCTGATGT & X74568 & {$[34]$} \\
& (S) ATGAACTCCCTCTCCACAAGC & M86722 & {$[28]$} \\
IFN- $\gamma$ & (AS) TGGCTTTGTCTGGATTCTTTC & & \\
& (S) GTTTTTCTGGCTCTTACTGC & X53085 & {$[6]$} \\
TNF- $\alpha$ & (AS) CTTCCGCTTTCTTAGGTTAG & & \\
& (S) ATCGGCCCCCAGAAGGAAGAG & M29079 & {$[25]$} \\
iNOS & (AS) GATGGCAGAGAGGAGGTTGAC & X54859 & {$[18]$} \\
\multirow{2}{*}{$\beta-$ actin } & (S) GTCCAACCTGCAGGTCTTCG & X73029 & {$[24]$} \\
& (AS) CCATGATGGTCACATTCTGC & & \\
& (S) GGACTTCGAGCAGGAGATGG & U07786 & {$[1]$} \\
\hline
\end{tabular}

S: sense primer, AS: antisense primer.

\subsection{Pro-inflammatory cytokine gene expression by RT-PCR}

\subsubsection{LPS challenge}

A total of 12 pigs were challenged with $1 \mu \mathrm{g}$ lipopolysaccharide per $100 \mathrm{~g}$ BWT by intraperitoneal injection, and sacrificed after three hours. The mRNA expression of different cytokines including IL-1 $\beta$, IL-2, IL-6, IFN- $\gamma$, TNF- $\alpha$, iNOS and $\beta$-actin were determined using the RT-PCR semiquantitative method.

\subsubsection{Total RNA and RT-PCR}

Total RNA from spleen tissue $(0.2 \mathrm{~g})$ was extracted by Ultraspec and reverse transcription was performed. Different cytokine oligonucleotides listed in Table II were applied to amplify specific amplicons of the reverse transcripted cDNA. The RT-PCR products were loaded on a $1 \%$ agarose gel for electrophoresis analysis; the agarose gel was analyzed by realtime image capture for quantitative analysis with a control of $\beta$-actin. The cytokine gene was expressed as relative intensities of $\beta$-actin.

\subsection{Examination of visceral pathology}

The liver, spleen, lymph nodes and uterus were fixed in $10 \%$ neutral formalin and embedded in paraffin. Cross-thin sections were stained with hematoxylin and eosin, and the sections were examined for histopathology alteration under light microscopy.

\subsection{Statistical analysis}

All data were analyzed using the General Linear Models procedure [31]. Differences between individual means are determined by the Duncan new multiple range test.

\section{RESULTS AND DISCUSSION}

\subsection{Growth performance}

The results of DON and ZON on growth performance in pigs are summarized in Table III. There were significantly lower $(P<$ 0.05 ) body weight gains at the 16th day and final day of the experimental period in the Toxins group compared to the other 
Table III. Effects of DON and ZON on growth performance in pigs ${ }^{\dagger}$.

\begin{tabular}{lcccccc}
\hline Treatment & Control & Toxins & Toxins+ MDE & MDE & RSD & Significance \\
\hline Initial weight (kg) & 9.0 & 8.9 & 9.1 & 8.9 & 0.4 & NS \\
Weight day 16th (kg) & $16.2^{\mathrm{a}}$ & $15.2^{\mathrm{b}}$ & $15.9^{\mathrm{a}}$ & $15.9^{\mathrm{a}}$ & 0.4 & $*$ \\
Final weight (kg) & $29.8^{\mathrm{a}}$ & $26.2^{\mathrm{b}}$ & $29.1^{\mathrm{a}}$ & $29.4^{\mathrm{a}}$ & 0.7 & $*$ \\
Daily feed intake (kg per d) & $1.14^{\mathrm{a}}$ & $0.82^{\mathrm{b}}$ & $1.01^{\mathrm{a}}$ & $1.14^{\mathrm{a}}$ & 0.04 & $*$ \\
ADG d1-16th (kg per d) & $0.45^{\mathrm{a}}$ & $0.38^{\mathrm{b}}$ & $0.43^{\mathrm{a}}$ & $0.44^{\mathrm{a}}$ & 0.02 & $*$ \\
ADG d17-28th (kg per d) & $0.67^{\mathrm{a}}$ & $0.55^{\mathrm{b}}$ & $0.65^{\mathrm{a}}$ & $0.67^{\mathrm{a}}$ & 0.09 & $*$ \\
ADG d29-36th (kg per d) & $0.57^{\mathrm{a}}$ & $0.48^{\mathrm{b}}$ & $0.55^{\mathrm{a}}$ & $0.57^{\mathrm{a}}$ & 0.02 & $*$ \\
Feed efficiency & $0.49^{\mathrm{b}}$ & $0.58^{\mathrm{a}}$ & $0.52^{\mathrm{b}}$ & $0.50^{\mathrm{b}}$ & 0.02 & $*$ \\
\hline
\end{tabular}

a, b Means within the same row without bearing the same superscripts differ significantly.

$* P<0.05 ; * * P<0.01 ;$ NS: $P>0.05$.

${ }^{\dagger}$ Growth performance was measured on pen basis with 4 pigs per pen and 3 pens per treatment.

treatments. Similar results were also observed in average daily gain from 3 different stages. From daily feed intake, data showed that feed intake was significantly decreased in the Toxins group. The results in the growth performance revealed that DON and ZON hampered growth response in pigs as early as the 16th day of the experiment. This could be due to feed refusal behavior caused by DON toxicity. However, no vomiting or mortality was observed in clinical observation throughout the entire period of the experiment. The worst feed efficiency in group Toxin1 also reflects the toxicity of DON and ZON mycotoxins. The MDE incorporated in the feed with mycotoxins (Toxins+MDE) counteracted the negative effects from mycotoxins, including body weight gain, feed intake and feed efficiency. There was no negative effect on growth performance in the MDE alone. Observations on the 7th day of the experiment were obvious vulva swelling seen in female pigs lasting until the end of the experiment in the Toxins group, however, no similar symptoms were observed in the other groups. Feeding ZON-contaminated diets to pigs indicated $1 \mathrm{ppm} \mathrm{ZON}$ as the minimum concentration to cause hyperestrogenism [14]. The exposure of $250 \mathrm{ppb}$ dietary ZON caused obvious hyper-estrogenism in this experiment, suggesting that the young pigs were sensitive to $\mathrm{ZON}$ mycotoxins.

Significantly decreased body weight gain, decreased slaughter weight and reduced feed utilization efficiency in growing pigs were observed for the group fed a diet containing $3.5 \mathrm{ppm}$ of DON [2]. In the current study, DON and ZON were incorporated at $1 \mathrm{ppm}$ and $250 \mathrm{ppb}$, respectively. Significantly depressed growth parameters were demonstrated in our results, and a similar result has also been reported by Doll et al. [7], showing that Fusarium toxin contaminated maize (1.2 ppm ZON and $8.6 \mathrm{ppm}$ DON) incorporated into a maize basal diet for piglets at $50 \%$ (equal to $600 \mathrm{ppb} \mathrm{ZON}$ and $4.3 \mathrm{ppm}$ DON) at the expense of control maize. Consequently the voluntary feed intake and body weight gain of the animals receiving the highest proportion of Fusarium toxin contaminated maize was significantly decreased; however, the feed conversion ratio was not affected, and the mean weight of the uterus related to the body weight of the animals in the same group was increased by almost $100 \%$ as compared to the control. The detrimental effects on growth performance by mycotoxins in the present study were alleviated by the addition of MDE (Toxins+MDE group). This implies that MDE could effectively spare the harmful activity 
Table IV. Effects of DON and ZON on some serum biochemistry parameters in pigs.

\begin{tabular}{lcccccc}
\hline Treatment & Control & Toxins & Toxins+ MDE & MDE & RSD & Significance \\
\hline Total protein (g per L) & $79.1^{\mathrm{a}}$ & $57.6^{\mathrm{b}}$ & $72.8^{\mathrm{a}}$ & $75.2^{\mathrm{a}}$ & 2.5 & $*$ \\
Albumin (g per L) & $46.4^{\mathrm{a}}$ & $34.9^{\mathrm{b}}$ & $42.5^{\mathrm{ab}}$ & $45.3^{\mathrm{a}}$ & 2.1 & $*$ \\
Globulin (g per L) & $32.7^{\mathrm{a}}$ & $22.6^{\mathrm{b}}$ & $30.3^{\mathrm{ab}}$ & $29.9^{\mathrm{ab}}$ & 2.2 & $*$ \\
ALB/GLO & 1.5 & 1.6 & 1.5 & 1.6 & 0.1 & NS \\
GGT (U per L $)^{\dagger}$ & $36.6^{\mathrm{c}}$ & $84.3^{\mathrm{a}}$ & $63.8^{\mathrm{b}}$ & $40.8^{\mathrm{c}}$ & 11.5 & $*$ \\
ALT (U per L) & $46.2^{\mathrm{c}}$ & $123.4^{\mathrm{a}}$ & $91.4^{\mathrm{b}}$ & $37.2^{\mathrm{c}}$ & 21.5 & $* *$ \\
AST (U per L) & $67.6^{\mathrm{b}}$ & $109.6^{\mathrm{a}}$ & $101.0^{\mathrm{a}}$ & $65.4^{\mathrm{b}}$ & 17.6 & $*$ \\
\hline
\end{tabular}

$\mathrm{a}, \mathrm{b}, \mathrm{c}$ Means within the same row without bearing the same superscripts differ significantly.

$* P<0.05 ; * * P<0.01 ;$ NS: $P>0.05$.

${ }^{\dagger}$ GGT: $\gamma$-glutamyltransferase; AST: aspartate aminotransferase; ALT: alanine aminotransferase.

of Fusarium mycotoxins in growth performance of growing pigs.

\subsection{Blood biochemistry}

Blood parameters might be used for an additional estimation of toxic effects on live animals. It is assumed that elevated activities of serum enzymes such as alanine aminotransferase (ALT) and aspartate aminotransferase (AST) might reflect the organ damage [4]. Table IV summarizes the effect of DON and ZON on some serum biochemistry in pigs. Group Toxins had the lowest level of total protein, albumin and globulin among the treatments. In general, a decreased percentage from $27 \%$ to $31 \%$ as compared to that of the control was observed. Furthermore, there was no significant difference among treatments in the albumin/globulin ratio. However, in the $\gamma$-glutamyltransferase (GGT), AST and ALT assay, the DON and ZON challenged (Toxins) group, show the highest enzyme activity in the serum, increased 2.3-2.6 fold compared to the control group. Even though MDE was incorporated in the diets (Toxins+MDE) at $1.5 \mathrm{~kg}$ per ton, the addition of MDE could not counteract the detrimental effect in GGT and AST, except in ALT. The measurements of the control and MDE groups fell in a normal range of
GGT (10-60 U per L), ALT (31-58 U per L), and AST (32-84 U per L) [15].

A similar challenge experiment has demonstrated that total serum protein significantly decreases using $60 \%$ contaminated maize (0.42 ppm ZON and $3.9 \mathrm{ppm}$ DON) [7]. The elevation of the serum albumin: globulin ratio was also observed in pigs fed Fusarium mycotoxincontaminated grains [30]. In the present study, however, albumin concentrations in pigs were not altered. It is possible that DON and other Fusarium mycotoxins directly affect globulin synthesis in the liver and compromise the immune response of pigs [30]. The alterations of GGT activities and urea concentrations were earlier observed in pigs fed contaminated grains [2], and might indicate the Fusarium mycotoxin induced hepatotoxicity. In the studies of Mikami et al. [20], the results indicated that DON induces apoptosis through the caspase-3 activation pathway and causes functional disorder in porcine hepatocytes.

\subsection{Immune responses}

Macrophages are responsible for presenting the antigen and for serving as supportive accessory cells to lymphocytes during the development of specific immunity. When lipopolysaccharide is added, 
Table V. Effects of DON and ZON on alveolar macrophage activities in pigs.

\begin{tabular}{lcccccc}
\hline Treatment & Control & Toxins & Toxins+MDE & MDE & RSD & Significance \\
\hline Chemotactic Index $^{\dagger}$ & $4.24^{\mathrm{a}}$ & $2.07^{\mathrm{b}}$ & $4.42^{\mathrm{a}}$ & $4.20^{\mathrm{a}}$ & 0.01 & $*$ \\
\% of phagocytic macrophages & $27.6^{\mathrm{a}}$ & $20.8^{\mathrm{b}}$ & $25.6^{\mathrm{ab}}$ & $25.2^{\mathrm{ab}}$ & 0.5 & $*$ \\
Candida albicans/macrophages & 1.81 & 1.51 & 1.17 & 2.02 & 0.1 & NS \\
\hline
\end{tabular}

$\uparrow$ Chemotaxis was expressed as a chemotactic index, which was obtained by dividing the value for chemoattracted macrophages by the value for randomly migrated macrophages in the negative control.

a, b Means within the same row without bearing the same superscripts differ significantly.

$* P<0.05 ; * * P<0.01$; NS: $P>0.05$.

macrophages are activated to be tumoricidal or microbiocidal and can release a variety of products [22]. Moreover, macrophages could secrete prostaglandin and cytokines to modulate the activity of lymphocytes and other macrophages [16]. Therefore, the cellular integrity and functions are also representative of the immuno-competence of animals. The results of alveolar macrophage activity in pigs are shown in Table V. In evaluation of chemotaxic ability, DON and ZON (Toxins) significantly impaired the ability of chemotaxis and showed only $49 \%$ in comparison with the control group. However, MDE incorporated in mycotoxin groups obviously alleviated the abilities of chemotaxis and phagocytosis, similar to the control group. A similar trend was also found in the percentage of phagocytic macrophages; for the Toxins group a significantly lower level was recorded than that of the control, indicating that this phenomena might be due to the inhibition of phagocytic ability and lower numbers of functional intact cells.

There was no significant difference in the numbers of Candida albicans phagocytosed per macrophage among treatments. The fusarium toxin such as DON causes histopathological lesions including cellular necrosis and karyorrhexis in actively dividing tissues of the intestinal mucosa, bone marrow, spleen, testis and ovaries in experimental animals [5]. Therefore, macrophages, lymphocytes, and erythro- cytes may decrease with prolonged exposure to Fusarium mycotoxins [32]. The chemotaxic index is an important sign for the ability of macrophage movement toward pathogen invasion sites, showing obvious improvements by MDE supplementation after mycotoxin challenge in this study. Interestingly, the percentage of phagocytic macrophages was significantly depressed in the mycotoxin groups, however, they were not further elevated in the presence of MDE. This result suggests that the macrophages may be less sensitive to Fusarium mycotoxins challenged in $C$. albicans phagocytosis.

PR Vaccine was challenged on day 7 and 14 of the experiment, and serum was collected on the 14th and 28th day after vaccine inoculation. The effects of DON and ZON on anti-pseudorabies titer production of pigs are shown in Table VI. Generally, PR antibody titers were significantly decreased on day 28 and overall means in the Toxins group compared to that of the control. However, there was no significant difference in antibody titers on the 14th day. Some improvement was also noted when MDE was incorporated in the Toxins+MDE group, however, no significant difference in comparison with the Toxins group was found.

Furthermore, an increase of secondary antibody response but not in the primary response to tetanus toxoid in pigs fed Fusarium mycotoxin-contaminated wheat was observed [30]. The lack of an effect of 
Table VI. Effects of DON and ZON on anti-pseudorabies titer production of pigs.

\begin{tabular}{lcccccc}
\hline Treatment & Control & Toxins & Toxins+MDE & MDE & RSD & Significance \\
\hline 14th days $\mathrm{Ab}^{\dagger}$ & 0.59 & 0.62 & 0.57 & 0.68 & 0.01 & NS \\
28th days $\mathrm{Ab}$ & $7.21^{\mathrm{a}}$ & $6.19^{\mathrm{b}}$ & $6.82^{\mathrm{ab}}$ & $7.16^{\mathrm{a}}$ & 0.01 & $*$ \\
\hline
\end{tabular}

${ }^{\dagger}$ Pigs were challenged with PR inactivated vaccine at days 7 and 14 after the experiment started. Antibody titers were subjected to $\log 2$ transformation, 8 pigs were randomly selected for serum collection from thoracic vena cava per treatment.

a, b Means within the same row without bearing the same superscripts differ significantly.

$* P<0.05$; ** $P<0.01$; NS: $P>0.05$.

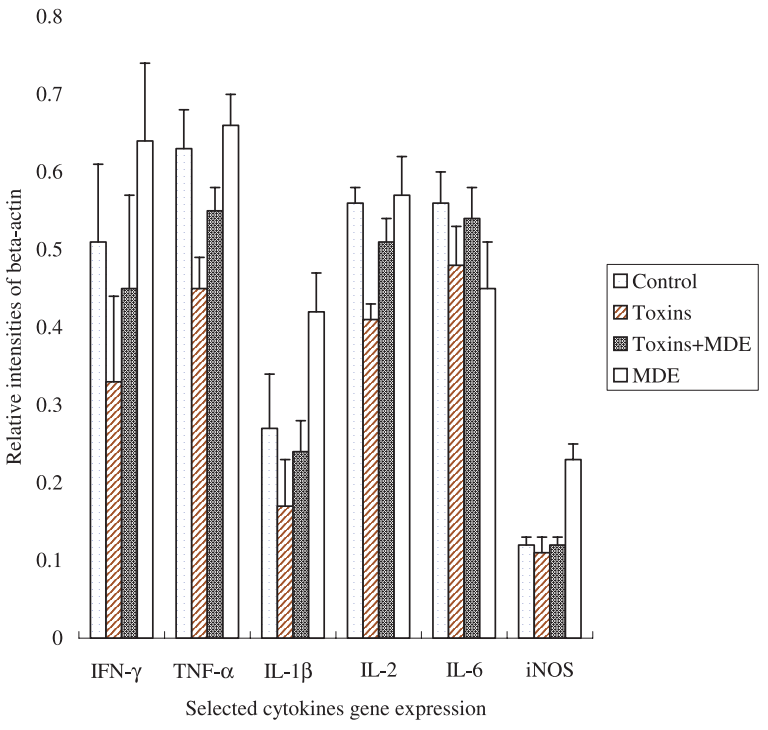

Figure 1. Quantification of regulatory and inflammatory cytokine mRNA levels in the spleen of pigs. Error bars represent the mean \pm SD of these results for different treatment $(n=4)$. feeding contaminated grains on the serum Ig concentrations of pigs in the present study was in contrast to past work. But due to the fact that the 28th day antibody mainly consists of Ig G, logically DON and ZON with confined levels in our study obviously resulted in depressed Ig G production. The Fusarium toxin impairing protein synthesis may be a reason for decreasing the antibody production.

The results of tested cytokine gene expression in the spleen of pigs are illustrated in Figure 1. All data are expressed as relative intensities of beta-actin, a housekeeping gene. DON and ZON challenged groups almost decreased the expression levels of all cytokines in this study, espe- cially IFN- $\gamma$, TNF- $\alpha$, IL- $1 \beta$, IL-2 and IL-6 had a much lower level. Interestingly, IFN$\gamma$, IL-1 $\beta$, and iNOS cytokine expressions were elevated by MDE alone and were even higher than the control group. An improvement of mRNA in different cytokines was observed in the Toxins+MDE group, this implies that MDE could alleviate the impairment effect in cytokine expression from toxins. It has been reported that a single oral exposure to both 5 and $25 \mathrm{mg}$ per $\mathrm{kg}$ body weight DON to mice significantly induces the mRNA for the proinflammatory cytokine interleukin (IL)-1 $\beta$, IL-6, and TNF- $\alpha$, IFN- $\gamma$, IL-2, IL-4 and IL10 expression [35]. However, sub-chronic levels of DON $(0,10$, and $25 \mathrm{ppm})$ fed for 
4 weeks increase mRNA expression only observed in IL-2, IFN- $\gamma$, IL-10 and TNF- $\alpha$ [36]. Similar results also demonstrate that DON ( $25 \mathrm{mg}$ per kg body weight) induces gene expression of IL- $1 \alpha$, IL- $1 \beta$, IL- 6 and IL-11 in mice [17]. In general, domestic animals are exposed to the mixtures of fungal toxins under field conditions as in the present study. Therefore, the present results could reflect a practical situation in the field for mild toxin levels and long-term (6 weeks) exposure. However, the effects of DON and ZON with potential immunotoxin mechanisms are still unknown.

\subsection{Histopathological examination}

The results of histopathological changes in the DON and ZON challenged groups (Toxins) showed multi-organ toxicity characteristics, including (1) hepatic blood vessel thickening and dilatation; (2) necrosis of lymphocytes and depletion in the spleen; (3) peripheral hemorrhage and focal necrosis in lymph nodes; (4) congestion or hyperemia of the uterus. However, a slight alteration of the liver was found in DON, ZON and MDE groups (Toxins+MDE). No histopathological alterations were observed in both control and MDE groups. Fusarium mycotoxins, like DON, contain a 12,13-epoxide ring in their chemical structure. This ring interacts with protein production since it binds to the large ribosomal subunit and subsequently blocks the unification of the small and large ribosomal sub-unit at translation. Additionally, it inhibits the inherent peptidyltransferase [9]. Therefore, cells or tissues with higher protein turnover rates are susceptible to DON. MDE is one kind of enzyme with epoxidase and esterase activities; epoxidase could block epoxide formation in DON metabolism and esterase transformed ZON into a non-toxic metabolite which has no estrogenic potential.
The cytotoxicity of DON in the liver has neither been reported in the nature nor experimentally. This might be due to the potential of liver regeneration and rapid clearance of apoptotic cells in vivo [13]. Therefore, only blood vessel thickening and dilation were found in current liver sections. The effect of DON and ZON on the uterus including congestion or hyperemia and the blood vessel dilatation was seen in the focal area. This result coincides with our observation that the uterine blood vessels were enlarged to twice the size of the other groups.

A previous report [14] indicates that the dosage of $\mathrm{ZON}$ at $1 \mathrm{ppm}$ is an important threshold for producing hyper-estrogenism in animals. However, $250 \mathrm{ppb} \mathrm{ZON}$ in the present study is far lower than the above level, and a hyper-estrogenic appearance in young female pigs remains to be elicited. This observation whether DON contributes someway to enhance ZON bioactivity in pigs needs to be further verified.

\section{CONCLUSION}

Overall, the results of this study imply that a combination of DON and ZON causes multi-organ toxicities in pigs. MDE, a mycotoxin deactivator, could provide a partial or complete toxic sparing effect from mycotoxins by different criteria including growth performance, serum biochemistry parameters, alveolar macrophage activities, antibody titers, and cytokine secretion profile and histopathological observations. These findings suggest that the levels below the critical value of DON and ZON for domestic animals published by BML [3], (DON $1 \mathrm{mg}$ per $\mathrm{kg}$ and $\mathrm{ZON} 0.25 \mathrm{mg}$ per $\mathrm{kg}$ for starting and finishing pig diets) still have some adverse and toxic effects on pigs.

\section{REFERENCES}

[1] Baarsch M., Inflammatory cytokine expression in acute porcine pleuropneumonia, 
Thesis, University of Minnesota, USA, 1994.

[2] Bergsjo B., Langseth W., Nafstad I., Jansen J.H., Larsen H.J., The effects of naturally deoxynivalenol-contaminated oats on the clinical condition, blood parameters, performance and carcass composition of growing pigs, Vet. Res. Commun. 17 (1993) 283-294.

[3] BML (The German Federal Ministry of Nutrition, Agriculture and Forestry), Orientation values for critical concentrations of deoxynivalenol and zearalenone in diets for pigs, ruminants and gallinaceous poultry, VDM 27/00 (2000) 2-3.

[4] Cheng Y.H., Shen T.F., Pang F., Chen B.J., Effects of aflatoxin and carotenoids on growth performance and immune response in mule ducklings, Comp. Biochem. Phys. C 128 (2001) 19-26.

[5] Ciegler A., Trichothecenes: Occurrence and toxicoses, J. Food Protect. 41 (1978) 399 403.

[6] Dijkmans R., Vandenbroeck K., Beuken E., Billiau A., Sequence of the porcine interferon-gamma (IFN-gamma) gene, Nucleic Acids Res. 18 (1990) 4259.

[7] Doll S., Danicke S., Ueberschar K.H., Valenta H., Schnurrbusch U., Ganter M., Klobasa F., Flachowsky G., Effects of graded levels of Fusarium toxin contaminated maize in diets for female weaned piglets, Arch. Tierernahr. 57 (2003) 311-314.

[8] Etienne M., Jemmali M., Effects of zearalenone (F2) on estrous activity and reproduction in gilts, J. Anim. Sci. 55 (1982) 110.

[9] Feinberg B., McLaughlin C.S., Biochemical mechanism of trichothecene mycotoxins, in: Bcasley V.R. (Ed.), Trichothecene Mycotoxicosis Pathological Effects, Boca Raton, FI, CRC Press, Vol. I, 1989, pp. 27-35.

[10] Green M.L., Stouffer D.K., Scheidt A.B., Long G.G., Diekman M.A., Evaluation of use of progesterone to counteract zearalenone toxicosis during early pregnancy in gilts, Am. J. Vet. Res. 52 (1991) 1871-1874.

[11] Green M.L., Diekman M.A., Malayer J.R., Scheidt A.B., Long G.G., Effect of prepubertal consumption of zearalenone on puberty and subsequent reproduction of gilts, J. Anim. Sci. 68 (1990) 171-178.

[12] Huether M.J., Lin G., Smith D.M., Murtaugh M.P., Molitor T.W., Cloning, sequencing and regulation of an mRNA encoding porcine interleukin-1 $\beta$, Gene 129 (1993) 285-289.
[13] Ihara T., Sugamata M., Sekijima M. Okumura H., Yoshino N., Ueno Y., Apoptotic cellular damage in mice after T-2 toxin-induced acute toxicosis, Nat. Toxins 5 (1997) 141-145.

[14] James L.J., Smith T.K., Effect of dietary alfalfa on zearalenone toxicity and metabolism in rats and swine, J. Anim. Sci. 55 (1982) $110-118$.

[15] Kaneko J.J., Harvey J.W., Bruss M.L., Clinical biochemistry of domestic animals, 5th Ed., Academic Press, California, USA, 1997.

[16] Kimball J.W., Introduction to Immunology, Macmillan Publishing Co., New York, 1990.

[17] Kinser S., Jia Q., Li M., Laughter A., Cornwell P., Corton J.C., Pestka J.J., Gene expression profiling in spleens of deoxynivalenol-exposed mice: immediate early genes as primary targets, J. Toxicol. Environ. Health A 67 (2004) 1423-1441.

[18] Kuhnert P., Wuthrich C., Peterhans E., Pauli U., The porcine tumor necrosis factorencoding genes: sequence and comparative analysis, Gene 102 (1991) 171-178.

[19] Lesson S., Diaz G.J., Summers J.D., Poultry metabolic disorders and mycotoxins, University Books, Guelph, Ontario, Canada, 1995.

[20] Mikami O., Yamamoto S., Yamanaka N., Nakajima Y., Porcine hepatocyte apoptosis and reduction of albumin secretion induced by deoxynivalenol, Toxicol. 15 (2004) 241249.

[21] Moore C.J., Blaney B.J., Spencer R.A., Dodman R.L., Rejection by pigs of mouldy grain containing deoxynivalenol, Aust. Vet. J. 62 (1985) 60-62.

[22] Nathan C.F., Secretory products of macrophages, J. Clin. Invest. 79 (1987) 319-326.

[23] Olsen M., Kiessling K.H., Species differences in zearalenone-reducing activity in subcellular fractions of liver from female domestic animals, Acta Pharmacol. Toxicol. 52 (1983) 287-291.

[24] Pampusch M.S., Bennaars A.M., Harsch S., Murtaugh M.P., Inducible nitric oxide synthase expression in porcine immune cells, Vet. Immunol. Immunop. 61 (1998) 279289.

[25] Pauli U., Beutler B., Peterhans E., Porcine tumor necrosis factor alpha: cloning with the polymerase chain reaction and determination of the nucleotide sequence, Gene 81 (1989) 185-191. 
[26] Prelusky D.B., The effect of deoxynivalenol on serotoninergic neurotransmitter levels in pig blood, J. Environ. Sci. Heal. B 29 (1994) 1203-1218.

[27] Rainey M.R., Tubbs R.C., Bennett L.W., Cox N.M., Prepubertal exposure to dietary zearalenone alters hypothalamo-hypophysial function but does not impair postpubertal reproductive function of gilts, J. Anim. Sci. 68 (1990) 2015-2022.

[28] Richards C.D., Saklatvala J., Molecular cloning and sequence of porcine interleukin 6 cDNA and expression of mRNA in synovial fibroblasts in vitro, Cytokine 3 (1991) 269-276.

[29] Rotter B.A., Prelusky D.B., Pestka J.J., Toxicology of deoxynivalenol (vomitoxin), J. Toxicol. Env. Heal. 48 (1996) 1-34.

[30] Rotter B.A., Thompson B.K., Lessard M., Trenholm H., Tryphonas L.H., Influence of low-level exposure to Fusarium mycotoxins on selected immunological and hematological parameters in young swine, Fund. Appl. Toxicol. 23 (1994) 117-124.

[31] SAS Institute, Users Guide, Basics, Release 6.03 Edition, SAS Institute Inc., Cary, NC, 1988.
[32] Segal R.I., Milo-Goldzweig A., Joffe Z., Yagen B., Trichothecenes induced haemolysis. 1. The haemolytic activity of T-2 toxin, Toxicol. Appl. Pharm. 70 (1983) 3.

[33] Smith T.K., MacDonald E.J., Effect of fusaric acid on brain regional neurochemistry and vomiting behavior in swine, $\mathrm{J}$. Anim. Sci. 69 (1991) 2044-2049.

[34] Vandenbroeck K., Fiten P., Beuken E., Martens E., Janssen A., Van Damme J., Opdenakker G., Billiau A., Gene sequence, cDNA construction, expression in Escherichia coli and genetically approached purification of porcine interleukin-1 $\beta$, Eur. J. Biochem. 217 (1993) 45-52.

[35] Zhou H.R., Yan D., Pestka J.J., Differential cytokine mRNA expression in mice after oral exposure to the trichothecene vomitoxin (deoxynivalenol): dose response and time course, Toxicol. Appl. Pharm. 144 (1997) 294-305.

[36] Zhou H.R., Yan D., Pestka J.J., Induction of cytokine gene expression in mice after repeated and sub chronic oral exposure to vomitoxin (Deoxynivalenol): differential toxininduced hyporesponsiveness and recovery, Toxicol. Appl. Pharm. 151 (1998) 347-358. 